\title{
Indirect arterial pulse tracings in children with coarctation of the aorta before and after operation
}

\author{
M OYONARTE, D F DICKINSON, D MEDICI, AND D I HAMILTON \\ From the Regional Paediatric Cardiothoracic Unit, Royal Liverpool Children's Hospital, \\ Myrtle Street, Liverpool
}

ABSTRACT Eleven children with coarctation of the aorta were investigated before and aftef
surgical treatment, using simultaneous indirect carotid and femoral artery pulse wave tracing
The timing of the onset of the femoral pulse in the children with coarctation, both before and
after operation, did not differ significantly from normal. However, the time interval betwee
the peak of the femoral pulse and the dicrotic notch of the carotid pulse was signiff
cantly shorter than normal in the children with coarctation before operation. After operation
the peak femoral to carotid dicrotic notch time interval was restored to normal. It is suggested
that this simple non-invasive test might be of value in the long-term follow-up of patients afte
operation for coarctation of the aorta, particularly in those undergoing operation early in
childhood, to detect residual or recurrent coarctation.

The first use of synchronous indirect radial and femoral artery pulse recording in coarctation of the aorta was reported by Scheele. ${ }^{1}$ Since then, further studies have shown the value of the technique. ${ }^{2} 3$ However, although direct intra-arterial measurements of femoral and radial artery pulse pressure have been made before and after surgical repair of coarctation, ${ }^{45}$ no study using indirect assessment has been reported. The potential value of a simple non-invasive technique which supplements clinical examination is considerable, particularly in the paediatric age group. We have studied a group of children undergoing surgical treatment for coarctation of the aorta in order to assess the use of indirect pulse recordings.

\section{Patients and methods}

Eleven children with coarctation of the aorta were studied at the Royal Liverpool Children's Hospital. The diagnosis was confirmed by cardiac catheterisation and angiography as part of the routine preoperative assessment, and in nine cases direct arterial pressure gradients across the site of coarctation were recorded. Full clinical details of the cases are given in the table. Eleven normotensive children without cardiovascular abnormalities,

Address for reprint requests: David I Hamilton, Royal Liverpool Children's Hospital, Myrtle Street, Liverpool L7 7DG.

matched for age with the children with coarctatio of the aorta, served as control subjects. Simu年 taneous indirect pulse recordings were obtaine from the left carotid and left femoral arteries using Statham Universal Transducing Cell, mode UC3, strain gauges, mounted in nylon holdes (Cambridge Instruments). Records were taken partial expiration on a Cambridge multichannal physiological recorder using a paper speed of 50 and $100 \mathrm{~mm} /$ second.

An ECG (lead II) and a phonocardiogram from the third intercostal space at the left sternal edge were recorded simultaneously. From these records two measurements were made each to the nearest five milliseconds. The delay in onset of the femoral pulse (onset time) was measured from the onset of the carotid pulse. The delay in the peate of the femoral pulse was measured as the time interval between the dicrotic notch of the carotid pulse and the peak of the femoral pulse (PF-CDN time). Where the peak of the femoril pulse fell later than the carotid dicrotic notch the time interval was recorded as a negative valuo. The carotid dicrotic notch was chosen as a usefuy fixed reference point on the arterial pulse wage which can be recognised by its relationship to the aortic component of the second heart sound. each case, five cardiac cycles were analysed, and a mean value for each measurement was obtainee 
Table Clinical data on eleven patients with coarctations

\begin{tabular}{|c|c|c|c|c|c|c|}
\hline \multirow[t]{3}{*}{ Patient } & \multirow{3}{*}{$\begin{array}{l}\text { Age at } \\
\text { operation } \\
\text { (yr) }\end{array}$} & \multicolumn{2}{|c|}{$\begin{array}{l}\text { Preoperative peak systolic arterial } \\
\text { pressure }(\mathrm{mm} \mathrm{Hg})\end{array}$} & \multirow[t]{3}{*}{ Surgical correction } & \multirow{2}{*}{\multicolumn{2}{|c|}{$\begin{array}{l}\text { Postoperative } \\
\text { sphygmomanometer } \\
\text { pressures }(\mathrm{mm} \mathrm{Hg})\end{array}$}} \\
\hline & & \multirow{2}{*}{$\begin{array}{l}\text { Ascending } \\
\text { aorta }\end{array}$} & \multirow{2}{*}{$\begin{array}{l}\text { Descending } \\
\text { aorta }\end{array}$} & & & \\
\hline & & & & & Arm & Leg \\
\hline 1 & 4 & 125 & 85 & Left subclavian flap aortoplasty & 85 & 80 \\
\hline 2 & 5 & $\overline{10}$ & 90 & End-to-end anastomosis & 105 & 110 \\
\hline 3 & 5 & 130 & 100 & Dacron gusset & 110 & 110 \\
\hline 4 & 7 & 150 & 95 & Dacron gusset & 130 & - \\
\hline 5 & 6 & - & 90 & End-to-end anastomosis & 100 & 90 \\
\hline 6 & 7 & 110 & 80 & End-to-end anastomosis & 105 & - \\
\hline 7 & 7 & 110 & 90 & End-to-end anastomosis & 110 & 一 \\
\hline 8 & 9 & 140 & 100 & Dacron gusset* & 115 & - \\
\hline 9 & 9 & 120 & 90 & Dacron gusset & 105 & 100 \\
\hline 10 & 13 & 140 & 95 & Dacron tube graft & 140 & 125 \\
\hline 11 & 15 & 140 & 110 & Dacron gusset* & 130 & 110 \\
\hline
\end{tabular}

*Operation for residual coarctation

These measurements are illustrated on the recording from a control patient in fig 1 . In the patients with coarctation of the aorta, further recordings were made six to eight weeks after operation. Student's $t$ test was used for statistical analysis of the data.

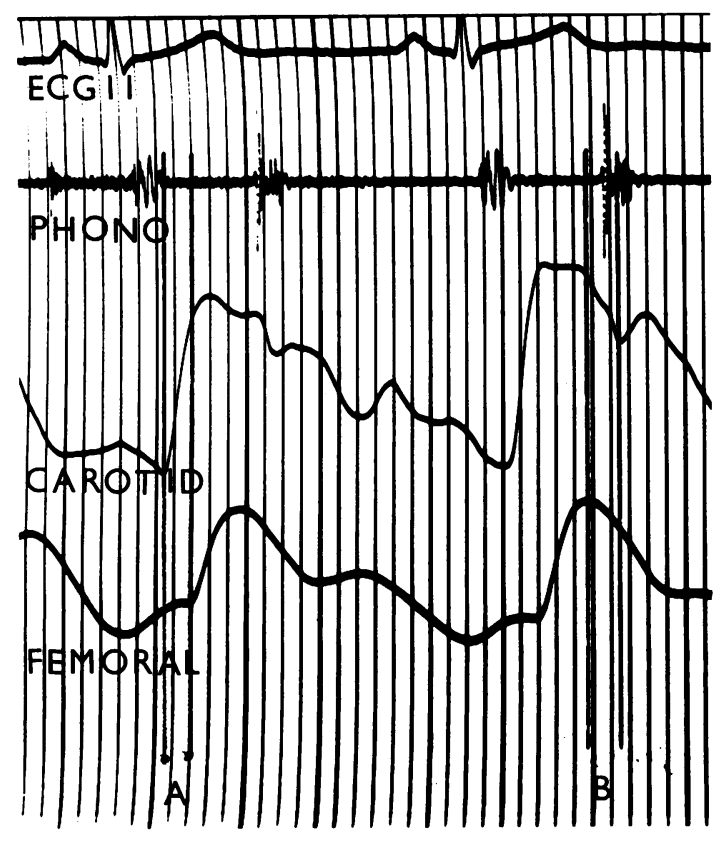

Fig 1 Simultaneous carotid and femoral pulse tracings from a normal control subject. Each vertical line indicates a time interval of 0.04 seconds. The time interval between the onset of the carotid and femoral pulses $(A)$ is approximately 0.06 seconds. The time interval between the peak of the femoral pulse and the dicrotic notch of the carotid pulse $(B)$ is approximately 0.07 seconds.

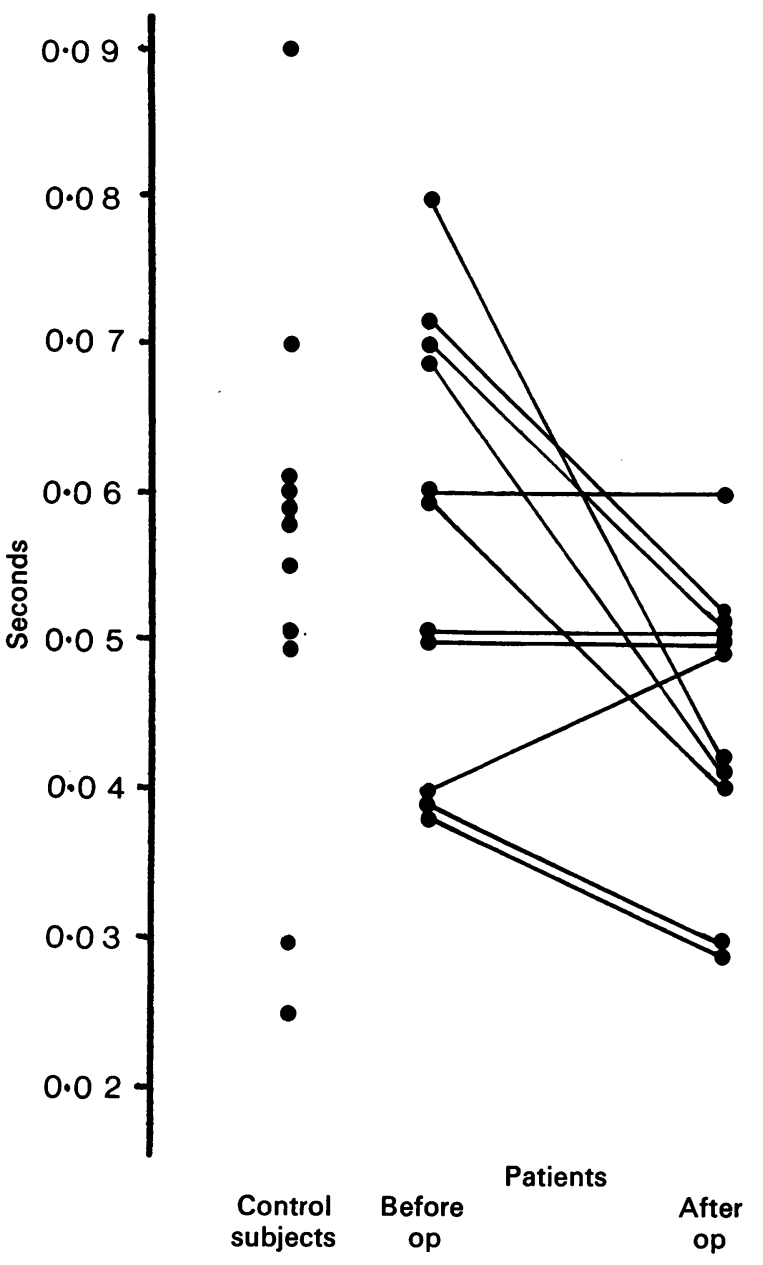

Fig 2 Time interval between the onset of the simultaneously recorded carotid and femoral pulses in normal control subjects and patients with coarctation of the aorta before and after operation. 


\section{Results}

The mean values of the measurements of onset time interval and PF-CDN time interval for each patient before and after operation, together with the results from the control subjects are given in figs 2 and 3 . The mean value for the onset time interval in the patients with coarctation before operation was 0.057 seconds (SD 0.014, range 0.04 to $0.08 \mathrm{~s}$ ). The value for the normal control sub-

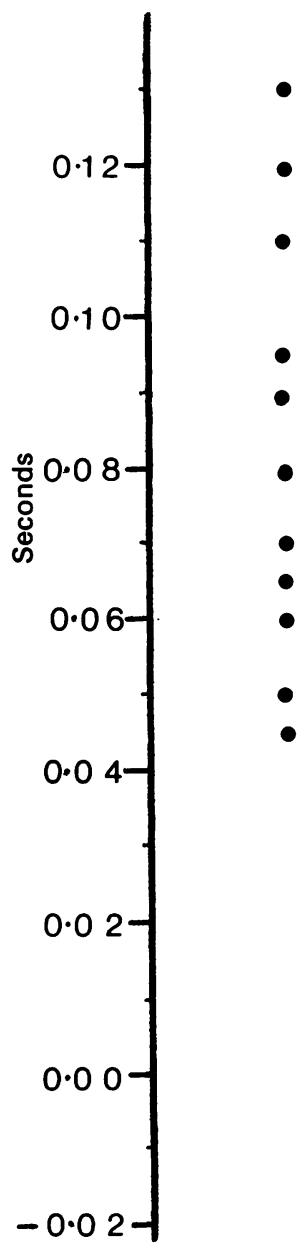

Control
Subjects

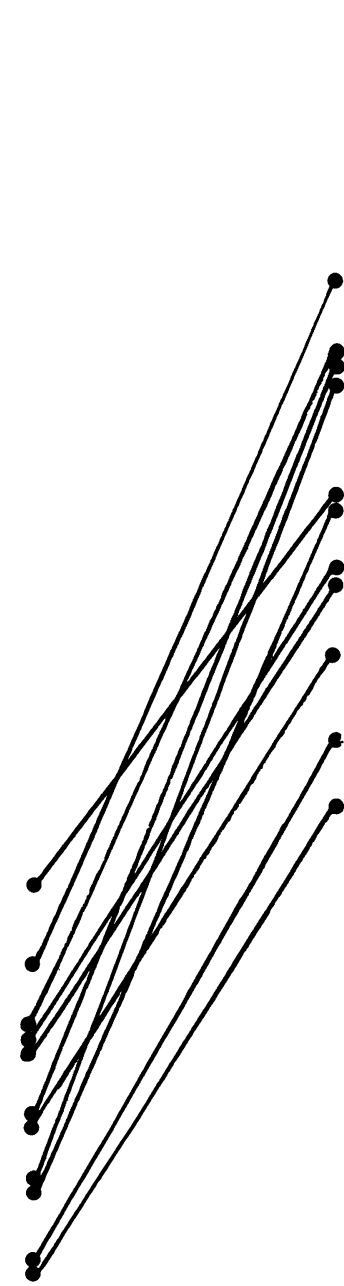

Patients
After op
Fig 3 Time interval between the peak of the femoral pulse and the dicrotic notch of the simultaneously recorded carotid pulse in normal control subjects and patients with coarctation of the aorta before and after operation.

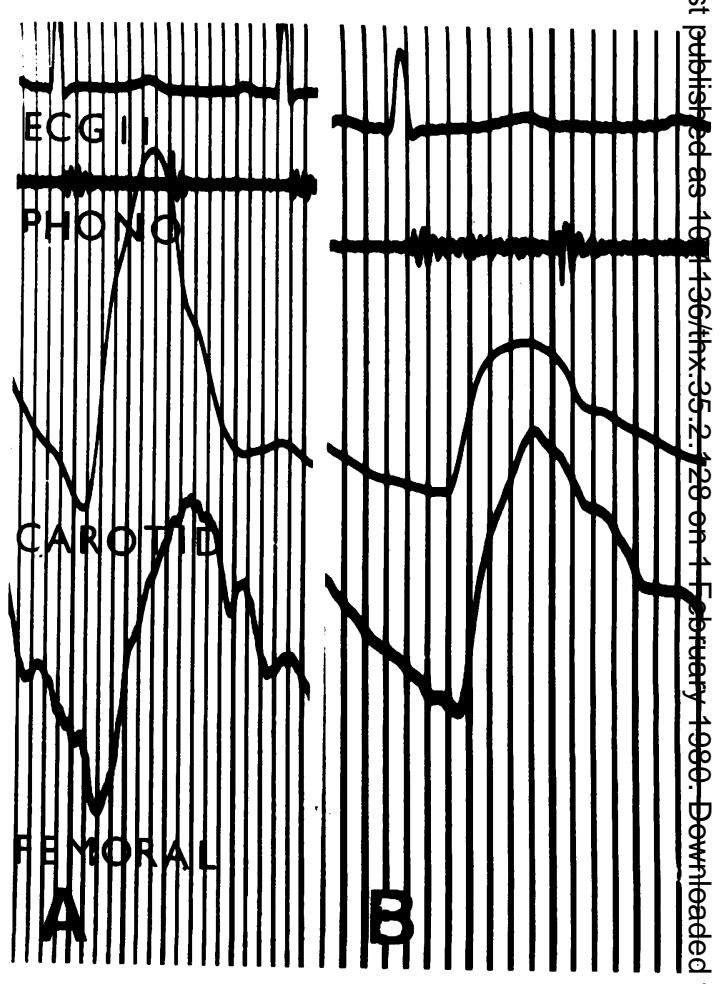

Fig 4 Simultaneous femoral and carotid artery pulse tracing from patient 8 . (A) Before operation. The onset of the femoral pulse is delayed 0.04 seconds after the onset of the carotid pulse, and the peak of the femoral pulse falls 0.03 seconds after the carotid dicrotic notch. (B) After operation. The onse of the femoral pulse is 0.03 seconds after the onset of the carotid pulse and the peak of the femoral pulse falls 0.08 seconds before the carotid dicrotic notch.

jects was 0.055 seconds (SD 0.018, range 0.025 to $0.09 \mathrm{~s})$. This difference is not significant. Aft operation, the mean onset time interval was 0.044 seconds (SD 0.01, range 0.03 to $0.06 \mathrm{~s}$ ). This significantly different from the preoperative valuo $(p<0.05)$ but not from the values in contras subjects $(\mathrm{p}<0.05)$.

The mean value for the PF-CDN time interva before operation in the patients with coarctation the aorta was 0.00 seconds (SD 0.016 , range -0.02 to $+0.03 \mathrm{~s}$ ), and significantly different $(p<0.001)$ from the mean of the normal contrg subjects $(0.083$ seconds, SD 0.028, range 0.045 $0 \cdot 13 \mathrm{~s})$. After operation, the mean PF-CDN value was 0.075 seconds (SD $0.021,1$ ange 0.04 to 0.1 sf ar.d differed significantly $(\mathrm{p}<0.001)$ from the pres operative value, but not from that of the norma 
control subjects $(p<0 \cdot 1)$. The pulse pressure recordings before and after operation from a patient with coarctation are illustrated in fig 4 . No correlation was found between either the onset time interval or the PF-CDN time interval and the peak systolic pressure gradient across the site of the coarctation before operation.

\section{Discussion}

Although considerable clinical importance has been given to the delay in the transmission of the arterial pulse wave to the lower extremity in coarctation of the aorta, published studies of directly or indirectly recorded femoral pulse waveform have failed to show a consistent delay in the onset of the femoral pulse as compared with upper limb pulses. ${ }^{4-6}$ Thus, although there is a tendency for the onset of the femoral pulse to be delayed beyond the onset of the radial pulse in patients with coarctation of the aorta, this is also true of a significant proportion of normal individuals. Conversely, in some patients with coarctation the onset of the femoral pulse has been shown to precede the onset of the radial pulse. ${ }^{3}$ Our present results confirm the wide range of values seen in normal individuals, which overlap extensively the ranges of values seen in patients with coarctation both before and after operation. Although there is a tendency for the onset time interval to shorten after operation (fig 2), in a number of cases no difference could be recorded.

Lewis ${ }^{6}$ emphasised that the clinically appreciated delay in the femoral pulse in coarctation was related to the slow ascent of the femoral pulse curve to a delayed peak. Kuhn et $a l^{3}{ }^{3}$ using indirect arterial pulse tracings, showed that the time interval between the delayed femoral peak and the dicrotic notch of a simultaneously recorded carotid pulse discriminated clearly between patients with coarctation and normal individuals. Our results endorse their findings. Although we were unable to show a correlation between preoperative PF-CDN time interval and directly measured pressure gradients, the restoration of the PF-CDN time interval to normal suggests a satisfactory result after operation. This view is supported by the work of previous authors, ${ }^{45}$ using directly measured pulse pressure tracings. It is of interest that although the PF-CDN time interval was significantly increased in all patients after operation, this increase was most marked in the youngest patient who underwent an angioplastic repair of the coarctation by subclavian flap aortoplasty. ${ }^{7}$ Conversely, the increase in PF-CDN time interval was least in the patient who required a complete Dacron tube graft to restore aortic continuity after resection of a hypoplastic segment $6 \mathrm{~cm}$ in length.

Several recent reports have shown a significant incidence of persistent hypertension after surgical repair of coarctation of the aorta. ${ }^{89}$ There is some evidence to suggest that early operation, probably before the age of 2 years, is more likely to result in a satisfactory postoperative blood pressure than if operation is delayed until later in childhood. ${ }^{89}$ However, end-to-end anastomosis of the aorta in early childhood is associated with a significant risk of persistent or recurrent coarctation during the growth period. ${ }^{10-12}$ Left subclavian flap aortoplasty appears to offer many advantages in this respect, ${ }^{713}$ but further evaluation over a longer period is necessary. Measurements of the PFCDN time interval provides a simple, non-invasive investigation which discriminates clearly between normal individuals and patients with coarctation. Serial recordings performed in the years after operation may therefore be useful in detecting residual obstruction at the operation site, and give a guide to the need for direct pressure measurement and angiography.

We would like to thank Dr E Epstein and Dr JL Wilkinson for their help and advice, Mr N Clarke for his technical assistance, and Mrs Sheila Critchley for secretarial help. D Medici was supported by a grant from the National Heart Research Fund.

\section{References}

1 Scheele CWL. Fall von stenose des isthmus aortae. Aus der medizinischen klinik des Professor Leyden zu Königsberg. Berliner Klinische Wochenschrift 1870; 7:32-8.

2 Björk S, Liedholm K. The femoral pulse curve in coarctation of the aorta. Acta Med Scand 1949; 136:97-103.

3 Kuhn LA, Sapin SO, Grishman A, Donoso E. The use of indirect arterial pulse tracings in the diagnosis of congenital heart disease. 1. Coarctation of the aorta. Pediatrics 1956; 18:193-204.

4 Brown GE, Clagett OT, Burchell HB, Wood EH. Pre-operative and post-operative studies of intraradial and intrafemoral pressures in patients with coarctation of the aorta. Mayo Clin Proc 1948; 23:352-8.

5 Hallenbeck GA, Wood EH, Burchell HB, Clagett OT. Coarctation of the aorta; the relationship of clinical results to cardiovascular dynamics studied before, during and after surgical treatment. Surg Gynecol Obstet 1951; 92:75-8. 
6 Lewis T. Material relating to coarctation of the aorta of the adult type. Heart 1931; 16:205-61.

7 Hamilton DI, Di Eusanio G, Sandrasagra FA, Donnelly RJ. Early and late results of aortoplasty with a left subclavian flap for coarctation of the aorta in infancy. $J$ Thorac Cardiovasc Surg 1978; 75:699-704.

8 Shinebourne EA, Tam ASY, Elseed AM et al. Coarctation of the aorta in infancy and childhood. Br Heart J 1976; 38:375-80.

9 Nanton MA, Olley PM. Residual hypertension after coarctectomy in children. Am J Cardiol 1976; 37:769-72.

10 Khoury GH, Hawes CR. Recurrent coarctation of the aorta in infancy and childhood. $J$ Pediato 1968; 72:801-6.

11 Hartmann AF, Goldring D, Hernandez A et al $\frac{\bar{v}}{\bar{v}}$ Recurrent coarctation of the aorta after success $-\widehat{\nabla}$ ful repair in infancy. Am J Cardiol 1970; 25:40510.

ڤ

12 Patel R, Singh SP, Abrams L, Roberts KD.Coarctation of the aorta with special reference to infants. Long term results of operation in $126 \vec{\omega}$ cases. Br Heart J 1977; 39:1246-53.

13 Pierce WS, Waldhausen JA, Berman W, Whitman V. Late results of the subclavian flap procedure in infants with coarctation of the thoracic aorta or Circulation 1978; 58:78-82. 